\title{
Research on the Analysis and Optimization Methods on the Current Situation of Domestic Rubbish Treatment
}

\author{
Zheng $\mathrm{HaO}^{1}$
}

${ }^{1}$ College of Renewable Energy, North China Electric Power University, Beijing 102206, China

\begin{abstract}
Keywords: Garbage, Recycling Economy Industrial Park, Landfill, Optimization Method, Community Research, Sustainable Development.
\end{abstract}

\begin{abstract}
At present,the relevant laws and procedures of garbage disposal in our country is gradually perfect stage.With the increasingly serious waste pollution, so the importance of living garbage disposal is very prominent.Through the "Chaoyang Circular Economy Park" and "Changping Asuwei landfill" and other companies and communities to conduct field research,wecan obtain the optimal treatment method ofdifferent component waste by using mathematical modeling methods, which is conducive to more convenient and quick to classify the garbage.
\end{abstract}

\section{Introduction}

The composition and characteristics of living garbageis affected by residents living standards, energy structure, seasonal changes and other factors, it has the characteristics of complexity, variability and regional differences.At present,garbage processing technology has three ways to deal with the landfill, incinerationand compostingin China, but due to the relevant laws and the process are still in the initial, the single a garbage processing technology has some disadvantages, and it will cause secondary pollution andresource waste, therefore it is urgent to find reasonable refuse comprehensive treatment method.From the perspective of energy conservation and recycling economy, garbage can be recycled after sorting, andthe comprehensive treatment of garbage is a development trend in the future.The treatment methods of domestic waste are different from the national conditions,thereforein order to find suitable for the garbage disposal technology of our country national conditions, we must make a thorough and comprehensive understanding for the situation and the processing technology of the garbage disposal.Therefore, through the combination method of landfill field investigation and in-depth resident questionnaire survey,we canmaster garbage treatment technology statusand existing problems,and based on actual survey data,we establish better waste disposal model, which canprovide theoretical support for thegarbage comprehensive utilized.

\section{The investigation of the Garbage Disposal Present Situation in Beijing}

The focus ofinvestigation is Chaoyang district andChangping district, these two areas use the combination mode of city life garbage disposal and suburban processing, we analyze the advantages and disadvantages of differentmodes, which can provide a referencefor different area garbage processing mode.Through access to literature, we found thatthe Beijing city garbage generates 16000 tonsevery day, the average per personper dayproduces 1 kggarbage, now garbageoccupys more than 20000 acres land in Beijingcity, each year shall be accounted for 500 acres landaccording 
to the current waste output.Open dumps not only affects the city landscape, but also pollutes the atmosphere, water and soil,which will pose a threat for the health of city residents.It is estimated that each year, the discarded renewable wastevalue up to 25 billion in an annual output of 1.5 tons garbage.In order to more detailBeijing waste comprehensive treatment situation,we visit the Beijing Changping districtAsuweiwaste landfill and Chaoyang circular economy industrial park.

In Asuwei waste sanitary landfill field, its leachate treatment process uses thedomestic advancedUASBF+A/O-MBR+NF+RO combination technology, the design capacity is 600 tons per day, the purified water up to Beijing local secondary emission standards, the part of the recycling is used for plant greening and road spraying dust.So,the treatment facilities are enable tofiltrate $\mathrm{N}$ pollutants and suspended matter in leachate, pollutant removal ratereached more than 99\%,the treatment facilities makesosmotic solution into clear and thorough and in line with national standardswater in garbage.

\section{Garbage Comprehensive Treatments}

This system uses the comprehensive treatment processbased on front sorting system and compost technology, and living garbagefirst carries out front sortingprocess. Through mechanical and manual sorting, the waste things (such as plastic, metal, etc.)in the hybrid, inorganic (such as gravel, rubble, etc.), the degradation of organic matter (such as leaves, fruit, etc.) can be completed separation. Available material enters the resource recycling system, inorganic material carries out landfill, the organic matter of composting degradation is made well-rotted manure and organic fertilizer to sell after the two-stage fermentation process, realizing the resources, reduction and harmless of urban domestic waste.

The whole Chaoyang economic industrial park is divided into four projects, and the different projects are responsible for different types' garbage disposal tasks. The whole industrial park not only develops the traditional garbage disposal mode, but also develops or introduces the new garbage disposal method.

The traditional mode of garbage disposal is mainly landfill and incineration.

Gaoantun sanitary landfill field covers an area of 4.164 hectares, the total volume is 892 million cubic meters, and domestic waste landfillcan be filled with 1000 tons every day.In the process of garbage disposal, we use the high density polyethylene film and bentonite pad double impermeable material, and the matching facilities include the leachate collection treatment system, the landfill gas collection treatment system, the underground water quality monitoring well and so on.At the same time,the use of landfill gas powercan givepower and heatingfor the workshop and officearea, in order to achieve energy-saving emission reduction and resource recycling.

In the investigation of waste disposal company,wealsoinvestigate and study on the surrounding community school.In order to make our investigation as far as possible comprehensive.Through the investigation of more than 100 residents of Longhua district and Huilongguan district, the 25 years oldaccounted for 14\%, 25 to 40 years old accounted for 30\%,40 to 60 years old accounted for 35\%, and 60 years old and above accounted for 21\%. Thestatistical data analysis shows thatdweller average per capita daily life trash quantity is about $0.8 \mathrm{~kg}$, and the proportion of all kinds of garbage is shown in Figure 1. 
C. Household paper $36 \%$

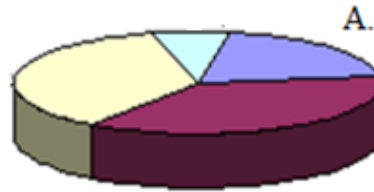

B.Food scraps and so on $37 \%$

A. Plastic products $20 \%$

Fig. 1 Composition of garbage

The only $7 \%$ peopleare relatively clear on the garbage specific classification and processing methods,83\%peoplehave an understanding of this, and 10\%people do not understand.Residents as the main source of living garbage,94\% are centralized waste treatment package,and few people will litter independent classification after treatment.Although people will carry out classificationin the garbage disposal field, and then to carry outre processing, but it will greatly reduce the efficiency of garbage disposal.With the development of a variety of garbage disposal technology,residents also have their more agree with the processing method as shown in Figure 2.

Which way do you agree more for landfill, incineration and composting?


Fig.2 People's public awareness of garbage disposal mode

The garbage should be classified processing, and different methods have advantages and disadvantages. Living garbage pollution is becoming more and more serious, and classification recycling is very necessary. Butit is still difficult, thin environmental awareness, weak propaganda,inadequate facilities and other aspects all cause recycling garbage classification difficult reason as shownin Figure 3.

What do you think of the difficulties in the implementation process of urban waste recycling?



Fig.3The reasons of residentwaste classification difficulties

In investigation,we collect a lot of data,and then carry out a mathematical modeling of the system and science.Based onanalytic hierarchy process,we can obtain the different kinds of garbage disposal optimization scheme. 
Reduction degree. It refers tothe amount of waste reduction through the program, and the amount of waste can be reduced the percentage of the total garbage to express. The degree of reduction directly reflectsthe urban waste treatment program.

Resource utilization. It refers to the use ofwaste resources, and it can be used asa percentage of the total amount of garbage.

Processing fee. Feeincludesthe investment of machine maintenance, labor costs and other expenses.The level of running cost is the most important indicator of a scheme.

Operation management. The governmentis the convenience degree of the management for the urban waste disposal system.

Environmental pollution.In the process of garbage transportation, storage and disposal, it causes the degree of environment pollution.

The degree of people's classification.Residents arelack of knowledge on the disposal of garbage,and itis difficult to realize the classification of garbage in the life.

\section{Domestic and International Several Important Garbage Disposal Method}

Incineration.The garbageis sent directly or mixed with a small amount of fuel to be sent to the incinerator to be burned, it produces heat, and then it can be used to make use of the heat energy and the amount of less stable solid residue.Heat can be used,and stable residue can be directly buried.After burning, it can destroythe virus andbacteria in the garbage, organic waste gas is decomposed at high temperature, the volume of wastecan also be reduced by $80 \%-90 \%$, and incineration process garbage can take the fastest speed to achieve the ultimate goal of reduction and harmless.

Compost. The use of a variety of microorganisms can be converted to organic matter degradation to stable humus in waste.According to thedifferent requirementsofmicroorganism in the process of composting, it can be divided into two types of aerobic and anaerobic, andaerobic composting efficiency is relatively higher.At present, people widelyuse high temperature aerobic compostingat home and abroad.

Sanitary landfill. Its garbage is placed in a relatively closed system, to reduce the minimum impact on the surrounding environment. At present, landfill is not only the main waste disposal methodpresent, but also other methodsof secondary waste final disposal way are essential.

\section{The Analytic Hierarchy Process to Determine the Optimization Model}

In this paper, plastic component as the example is theestablishment of the model to obtain its optimal processing program.

Principle Introduction. According to the problem nature and the overall goal, theproblem is decomposed into different components. And, according tothe interrelated effects between the factors and affiliationfactorswill carry out aggregation combination at different levels, forming a multi-level structure model.

Establishing Model and Solving. The target layer is the choice of a comprehensive optimal scheme; the criterion layeris the choice of the evaluation index, includingB1 reduction, B2 resource utilization,B3 processing costs,B4 operation management, B5 pollution and B6 resident classification degree; scheme layeris optional processing scheme, there are P1incineration, P2composting and P3 security landfill. 




I . According to the survey data, the matrix is established:

\begin{tabular}{|c|c|c|c|c|c|c|}
\hline A & B1 & B2 & B3 & B4 & B5 & B6 \\
\hline B1 & 1 & $1 / 2$ & $1 / 3$ & 3 & 1 & 2 \\
\hline B2 & 2 & 1 & $1 / 2$ & 3 & 2 & 4 \\
\hline B3 & 3 & 2 & 1 & 7 & 3 & 5 \\
\hline B4 & $1 / 3$ & $1 / 3$ & $1 / 7$ & 1 & $1 / 3$ & $1 / 2$ \\
\hline B5 & 1 & $1 / 2$ & $1 / 3$ & 3 & 1 & 2 \\
\hline B6 & $1 / 2$ & $1 / 4$ & $1 / 5$ & 2 & $1 / 2$ & 1 \\
\hline
\end{tabular}

$B 1=\left(\begin{array}{ccc}1 & 3 & 7 \\ 1 / 3 & 1 & 3 \\ 1 / 7 & 1 / 3 & 1\end{array}\right) ; \quad B 2=\left(\begin{array}{ccc}1 & 2 & 7 \\ 1 / 2 & 1 & 5 \\ 1 / 7 & 1 / 5 & 1\end{array}\right) ; \quad B 3=\left(\begin{array}{ccc}1 & 1 / 3 & 1 / 6 \\ 3 & 1 & 1 / 2 \\ 6 & 2 & 1\end{array}\right)$

$B 4=\left(\begin{array}{ccc}1 & 1 / 4 & 2 \\ 4 & 1 & 9 \\ 1 / 2 & 1 / 9 & 1\end{array}\right) ; \quad B 5=\left(\begin{array}{ccc}1 & 4 & 2 \\ 1 / 4 & 1 & 1 / 2 \\ 1 / 2 & 2 & 1\end{array}\right) ; \quad B 6=\left(\begin{array}{ccc}1 & 6 & 1 / 2 \\ 1 / 6 & 1 & 1 / 7 \\ 2 & 7 & 1\end{array}\right)$

II. Hierarchical single ordering and consistency checking

(1) We calculatetheabove matrix maximum eigenvalue $\lambda$ and the corresponding normalized characteristic matrix $\left\{w_{i 1}, w_{i 2}, \cdots w_{i n}\right\}$

(2)Definition consistency index is $C I=\frac{\lambda-n}{n-1}$

(3)The definition of random consistency index RI, and there are the table available RI=1.24.

\begin{tabular}{|c|c|c|c|c|c|c|c|c|c|c|c|}
\hline$n$ & 1 & 2 & 3 & 4 & 5 & 6 & 7 & 8 & 9 & 10 & 11 \\
\hline$R I$ & 0 & 0 & 0.58 & 0.90 & 1.12 & 1.24 & 1.32 & 1.41 & 1.45 & 1.49 & 1.51 \\
\hline
\end{tabular}

(4) When the consistency ratio $C R=\frac{C I}{R I}<0.1$,the degree of inconsistency matrix within the allowable range uses the normalized eigenvector as the weight vector,orto re construct the matrix should be adjusted.

Through the above steps, it can be calculated:

$A: w_{i}=[0.1807,0.3129,0.5289,0.0689,0.1807,0.0989]$

$\lambda_{\max }=6.0755, C I=0.0155, R I=1.24, C R=0.0125<0.1$ 


$$
\begin{aligned}
& B 1: \quad w_{i}=[0.6311,0.2287,0.0829] \\
& \lambda_{\text {max }}=3.007, C I=0.0035, R I=1.24, C R=2.28 \times 10^{-3}<0.1 \\
& B 2: \quad w_{i}=[0.5858,0.3299,0.0743] \\
& \lambda_{\text {max }}=3.014, C I=0.007, R I=1.24, C R=5.65 \times 10^{-3}<0.1 \\
& B 3: \quad w_{i}=[0.0997,0.2992,0.5983] \\
& \lambda_{\text {max }}=3, C I=0, R I=1.24, C R=0<0.1 \\
& B 4: \quad w_{i}=[0.1571,0.6535,0.0755] \\
& \lambda_{\text {max }}=3.0015, C I=0.0075, R I=1.24, C R=3.13 \times 10^{-2}<0.1 \\
& B 5: \quad w_{i}=[0.5904,0.1476,0.2952] \\
& \lambda_{\text {max }}=3, C I=0, R I=1.24, C R=0<0.1
\end{aligned}
$$

B6: $w_{i}=[0.3455,0.0689,0.5774]$

$$
\lambda_{\max }=3.032, C I=0.016, R I=1.24, C R=1.29 \times 10^{-2}<0.1
$$

Therefore, all matrices are satisfied with the consistency checkingcondition, and it doesn't need to be adjusted.

III. The level total ordering and its consistency checking

$$
\begin{aligned}
& W_{P 1}=\sum_{i=1}^{n=6} W_{A i} \cdot W_{B i 1}=0.5017 \\
& W_{P 2}=\sum_{i=1}^{n=6} W_{A i} \cdot W_{B i 2}=0.3813 \\
& W_{P 3}=\sum_{i=1}^{n=6} W_{A i} \cdot W_{B i 3}=0.4703 \\
& C I=\sum_{i=1}^{n=6} C_{i} I=0.0527, R I=0.9, C R=0.0585<0.1
\end{aligned}
$$

Because of the consistency of the test conditions, so $W_{P 1}>W_{P 3}>W_{P 2}$ isset up.

In summary, the plastic incineration is the best scheme.

Using the above methodcan respectivelyobtainoptimal scheme, namelywaste composition of composting has organic matter and food residue;the garbage compositionofincineration process has plastic garbage and non-plastic garbage;landfill waste composition hasglass, ceramic, ash, stone, cement block and so on. 


\section{Conclusions}

The relevant laws and procedures of the garbage disposal in our country are still at the beginning,the problems of domestic waste disposal are outstanding day by day, and we need to find the optimal scientific classification processing method of domestic refuse.In the year time, we visitthe Chaoyang circular economy park, and Changping Asuwei landfilland other companiesto conduct field research. After mastering a large number of data, using mathematical modeling method can obtain the optimal treatment method ofthe different composition of municipal solid waste (MSW), and puts forward reasonable suggestions.

\section{References}

[1] Chen Haibin, Deng Cheng, Mao Yi.Research on the technical and economic comparison of municipal solid waste recycling program.Chinese Journal of environmental engineering, 2014,1(1): 121-123.

[2] Rong Bo, Wei Panming, Li Yanfu, Li Yuchun. Research on the countermeasuresof MSW composition analysis and its corresponding treatment modein Beijing. Environmental protection, 2014(10): 67-69. 